\title{
When Reality Meets the Mobile Imaginary: Exploring Constraints in Mobile Technology Use
}

\author{
Catherine Middleton \\ Ted Rogers School of Management \\ Ryerson University \\ Presentation to the Materialities and Imaginaries of the \\ Mobile Internet Conference, February 2011 \\ http://www.materialities.ca/
}




\section{imaginaries}

- utopic future? possibility?

- start with the here and now:

- mobile

- seamless connectivity

- easy to use

- accessible

- affordable

- framework of constraints

- location of remedies 


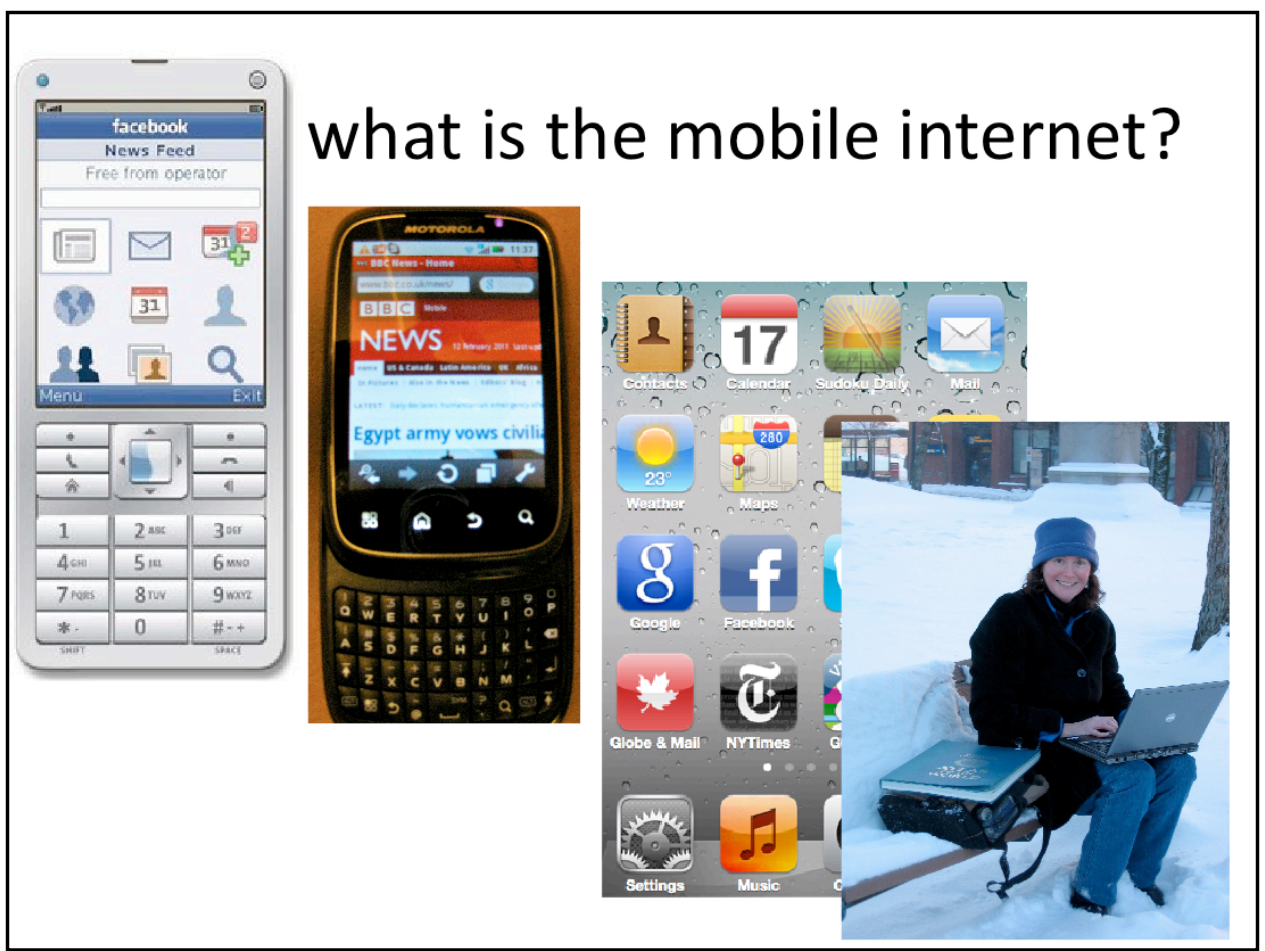

Facebook Zero app for 'feature' phones: https://mobilicity.ca/support/fbzero/Whatis-the-Facebook-Zero-App/

Opera browser on Android mobile

Apps on iPod touch/iPhone/iPad

laptop plus wifi (St John, New Brunswick) 


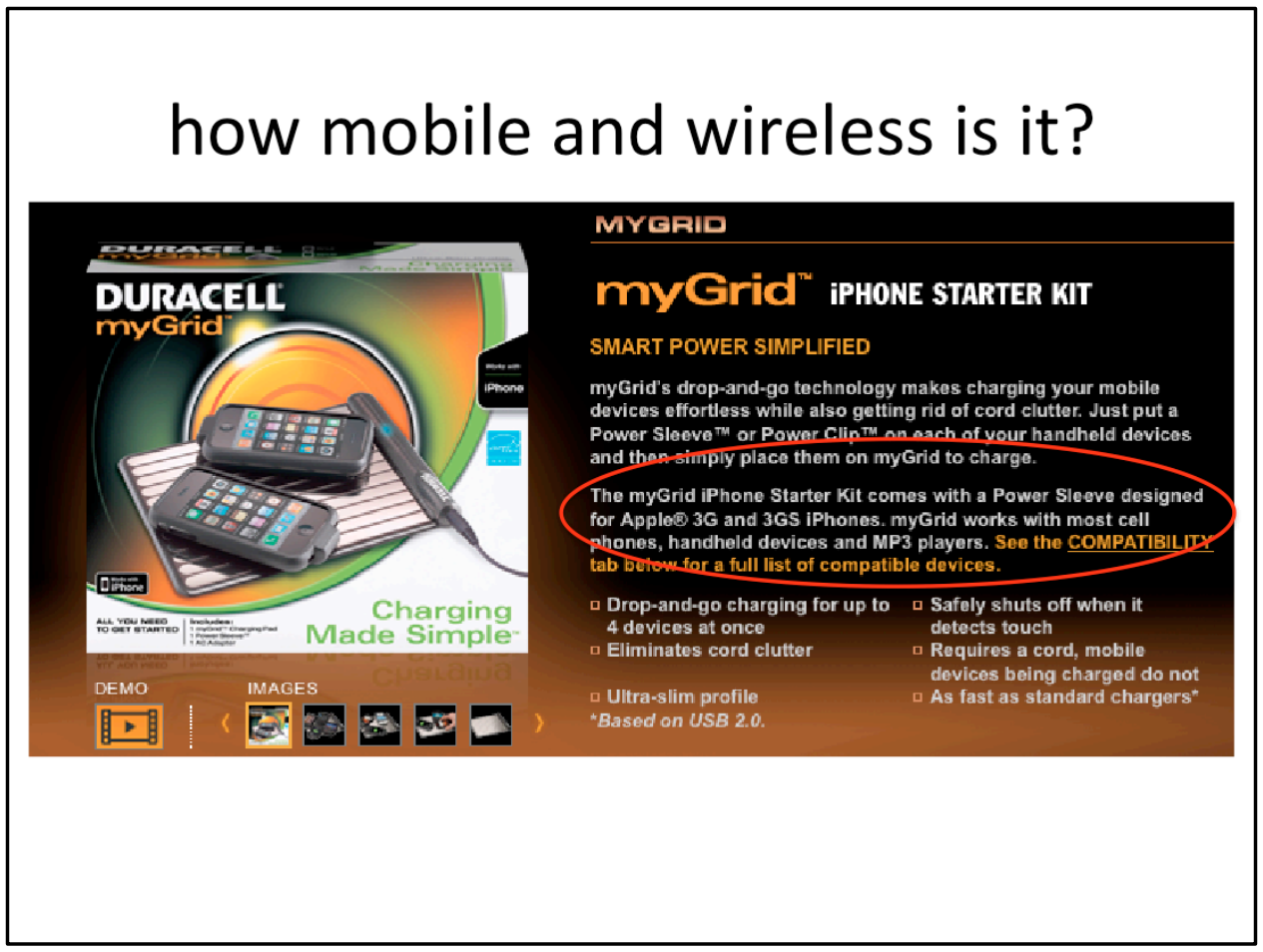

Duracell's wireless charger. Requires 'power sleeve' for each device, and wired connection for charging pad. http://www.duracell.com/en-US/product/mygrid-kitsiphone.jspx 


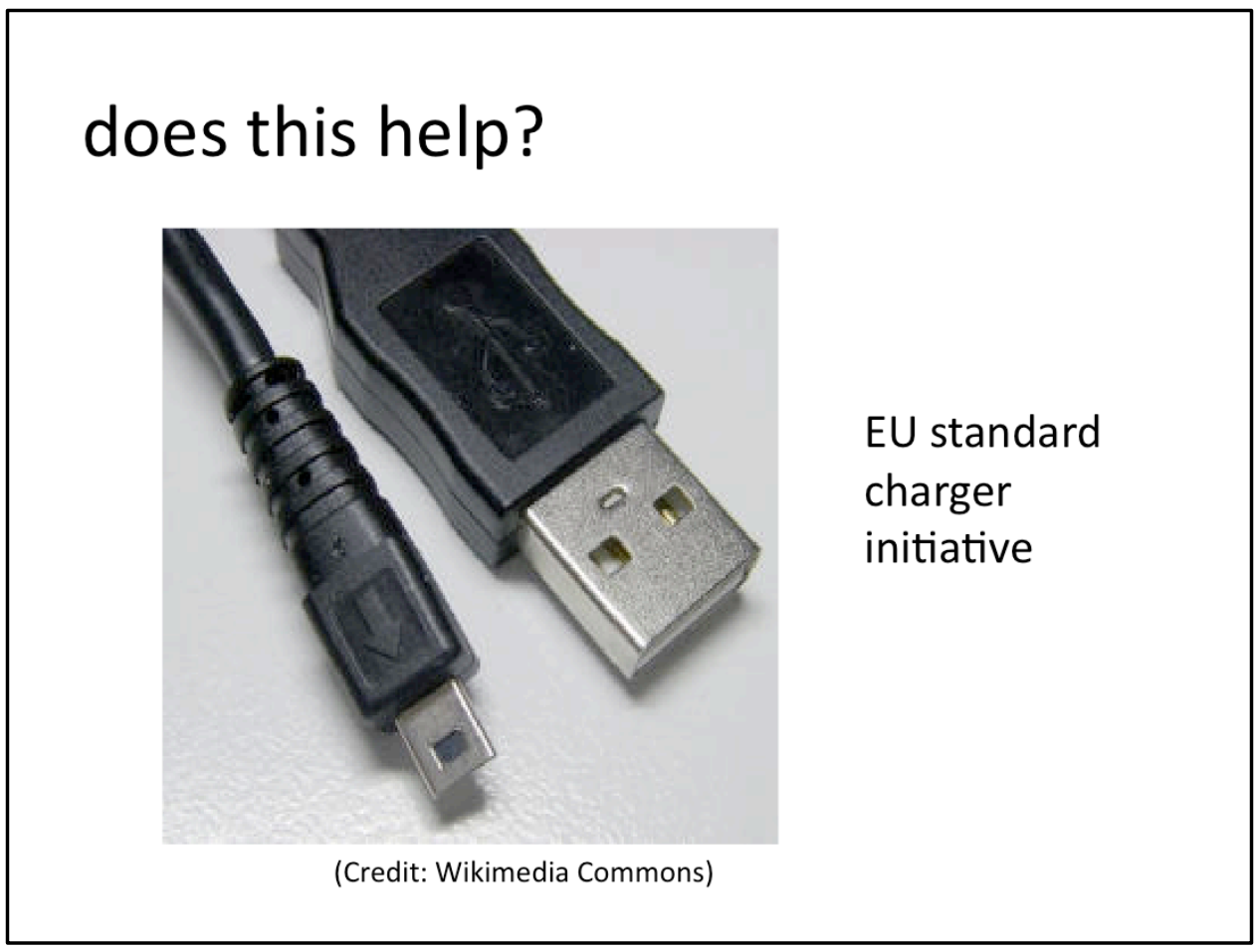

http://ec.europa.eu/enterprise/sectors/rtte/chargers/index_en.htm 


\section{mobile assemblages}
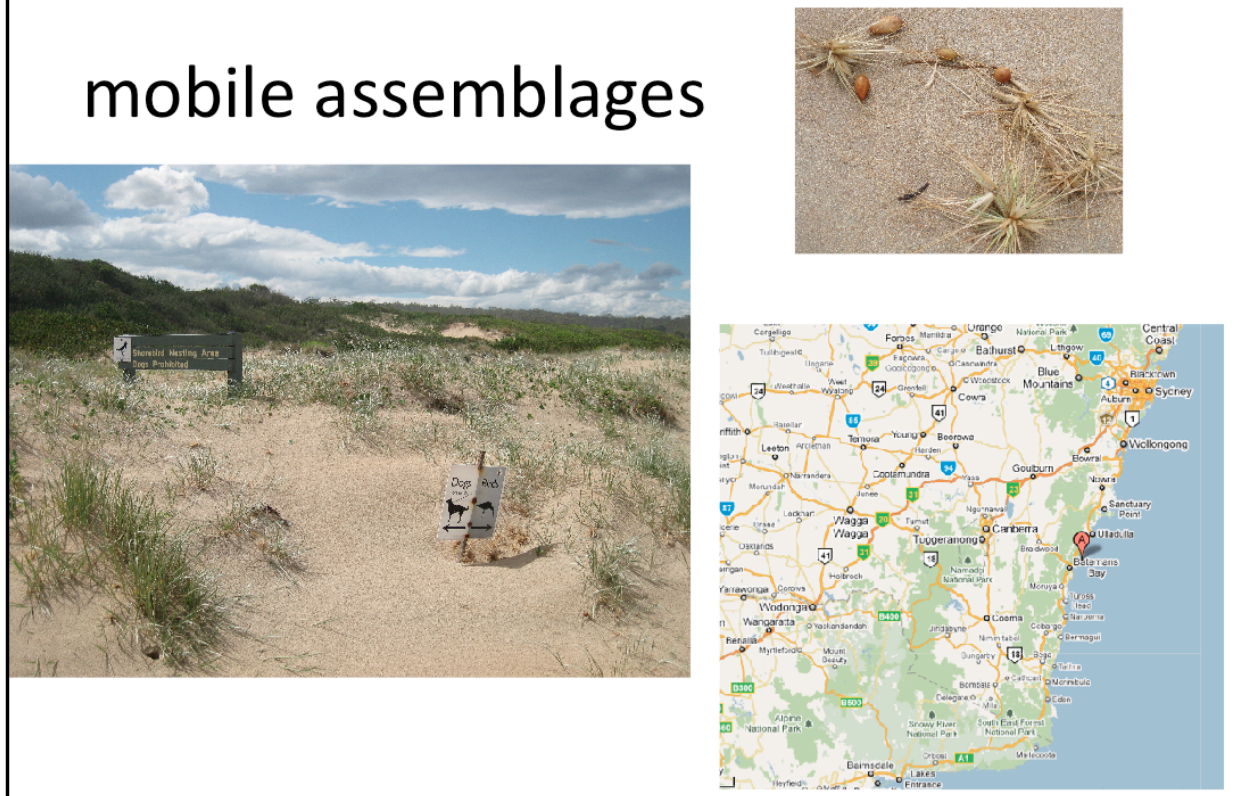

Getting broadband to the beach, Depot Beach, NSW, Australia. http://geobray.com/2010/01/19/broadband-3g-from-the-beach/ 


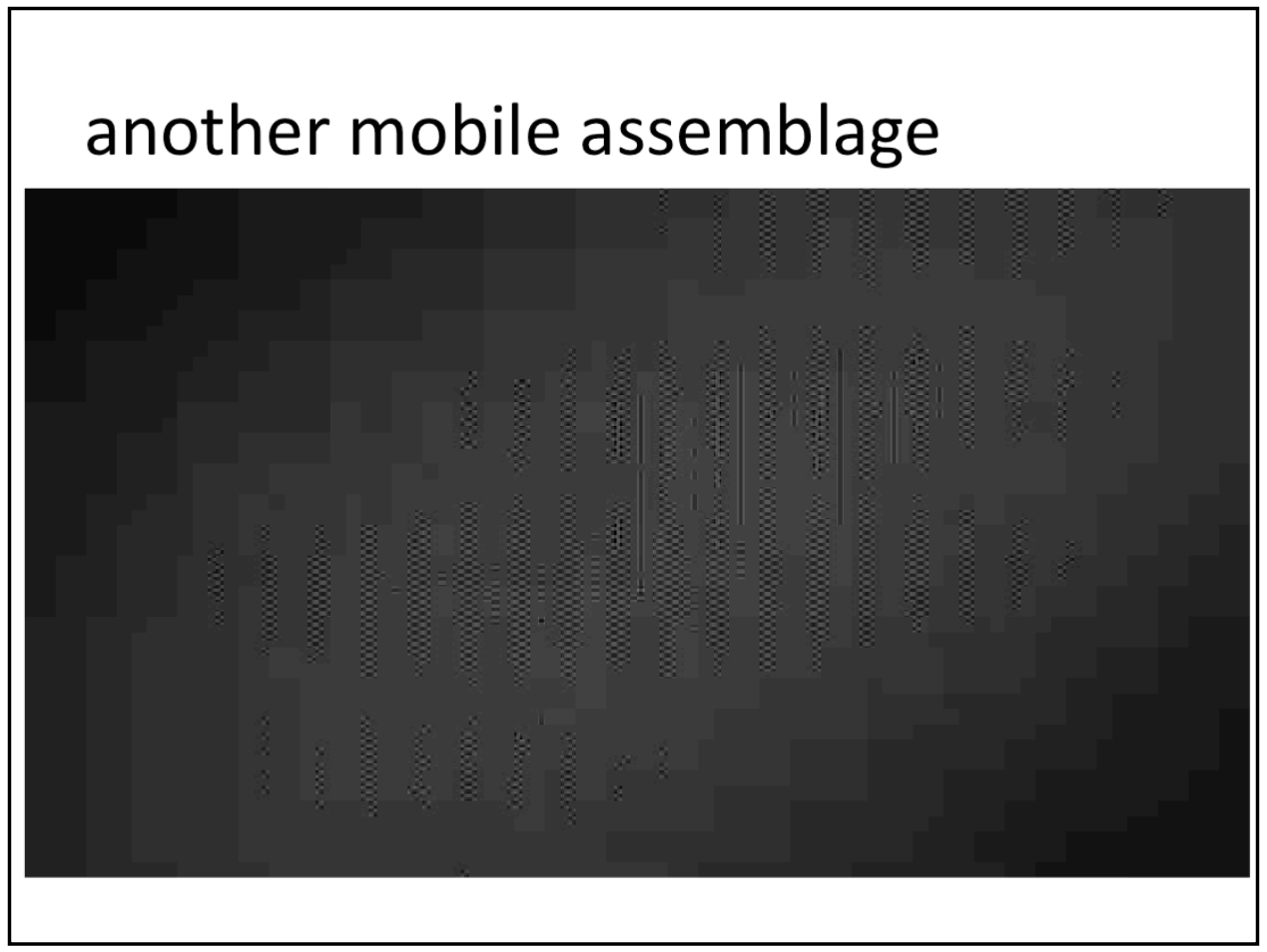

Video: http://geobray.com/2010/01/19/broadband-3g-from-the-beach/ 


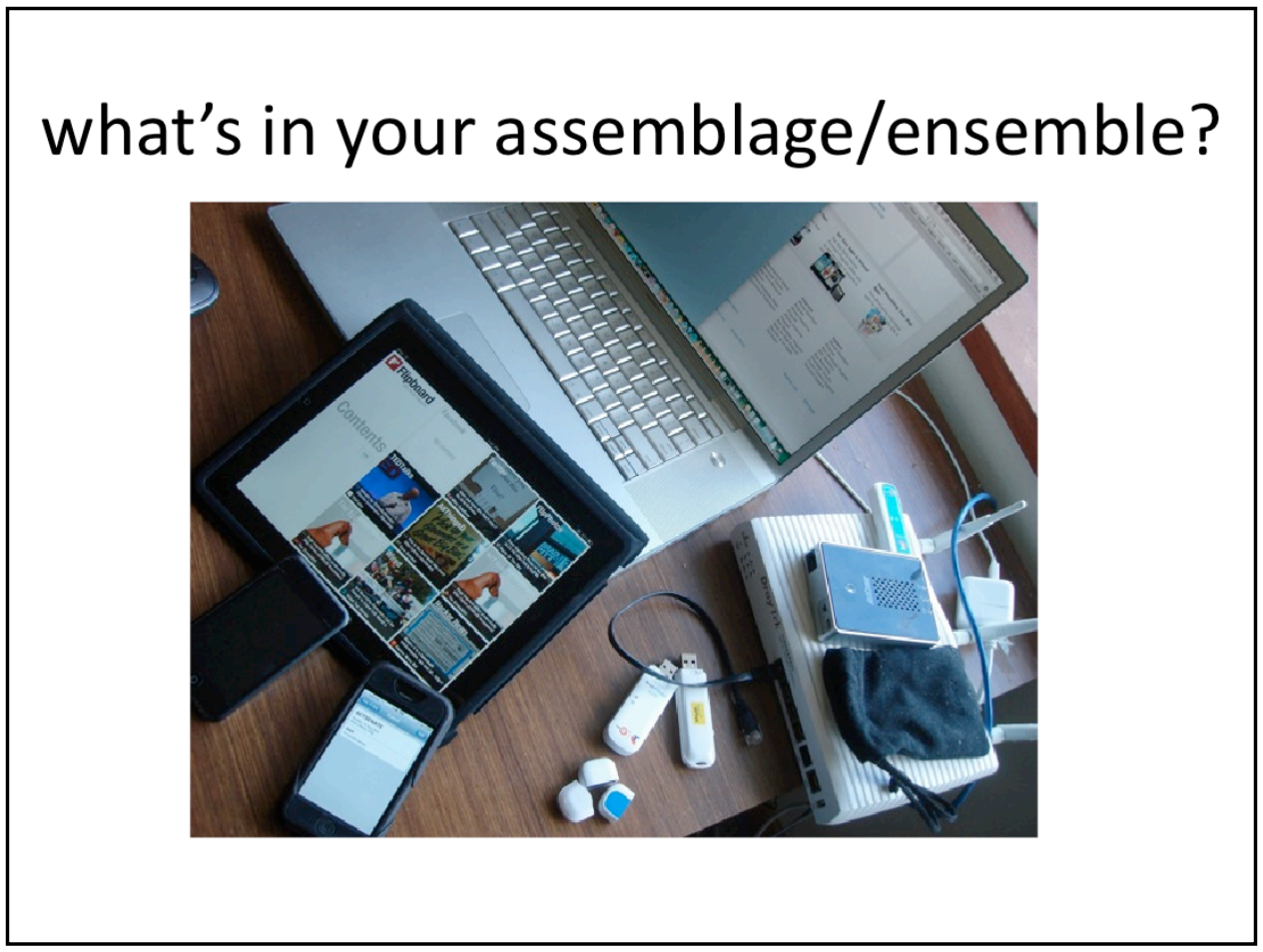

A mobile assemblage: Laptop, iPad, 2 iphones, 3 mobile broadband connections, portable router (battery powered), router. Photo: George Bray 


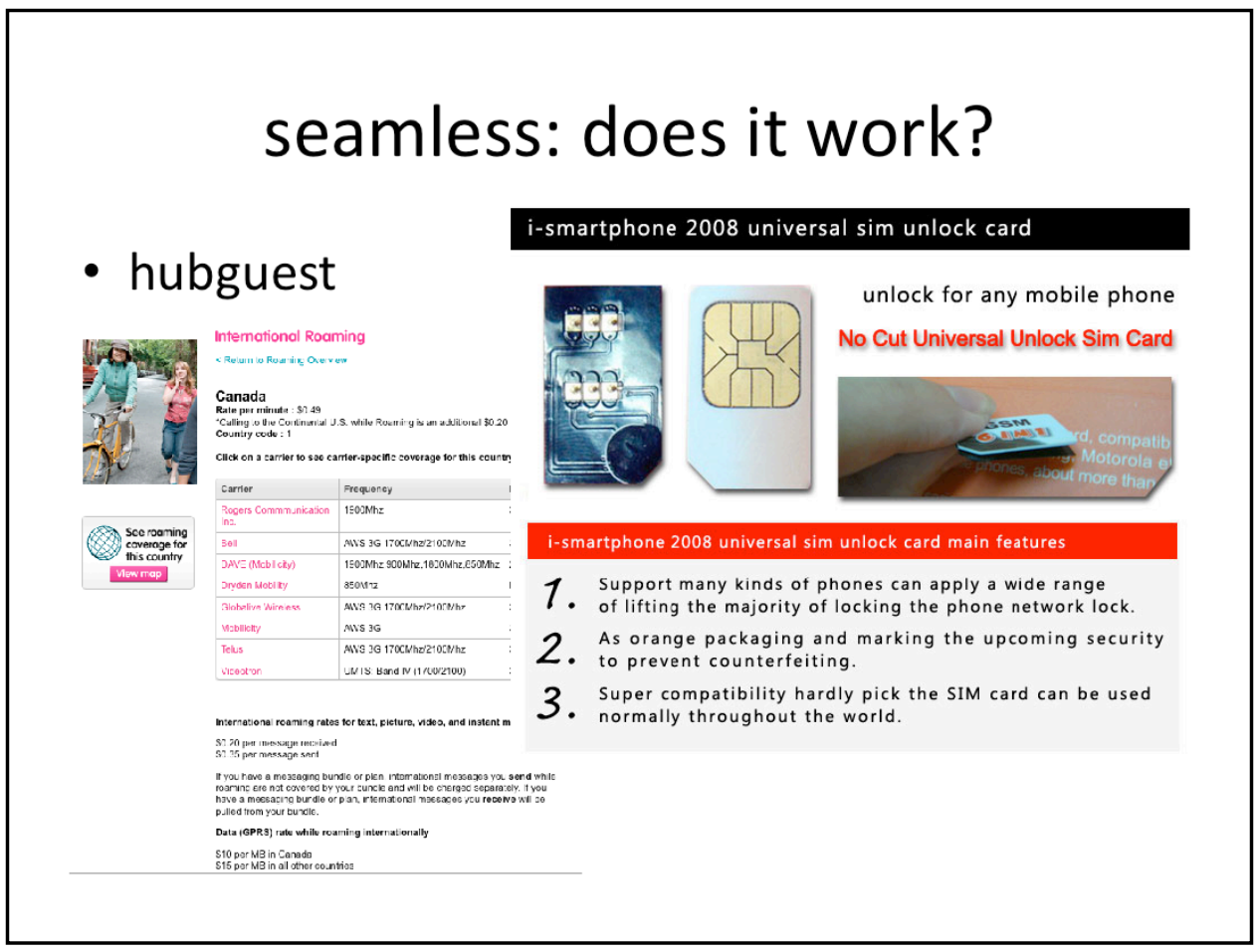

t-mobile roaming plans to Canada

sim card for use in multiple countries 


\section{seamless: does it work?}

Telus To Unlock Devices Beginning February I 5 For $\$ 50$

BY EX ON FEBRUARY 6TH, 2011

This week, Telus announced that the wireless company will be unlocking their IDEN/HSPA+ devices as of February 15, 2011 for a $\$ 50$ fee.

At first glance, this seems similar to the Rogers/Fido unlocking policy, but there is one major difference. The Telus unlocking policy is more flexible, not requiring customers to be on their contract for the full three year term before allowing the unlock.

Device unlocking applies to TELUS postpaid SIM -based devices that operate on the Telus IDEN and HSPA+ postpaid networks and meet the following conditions:

- The device must be in post-paid (paying a monthly bill or on a contract. Not a Pay and Talk customer) status for a minimum of 90 days.

- The device must be in post-paid status for a minimum of 90 days.

not easy to use a Canadian phone in other countries, it must be unlocked first, for a fee 


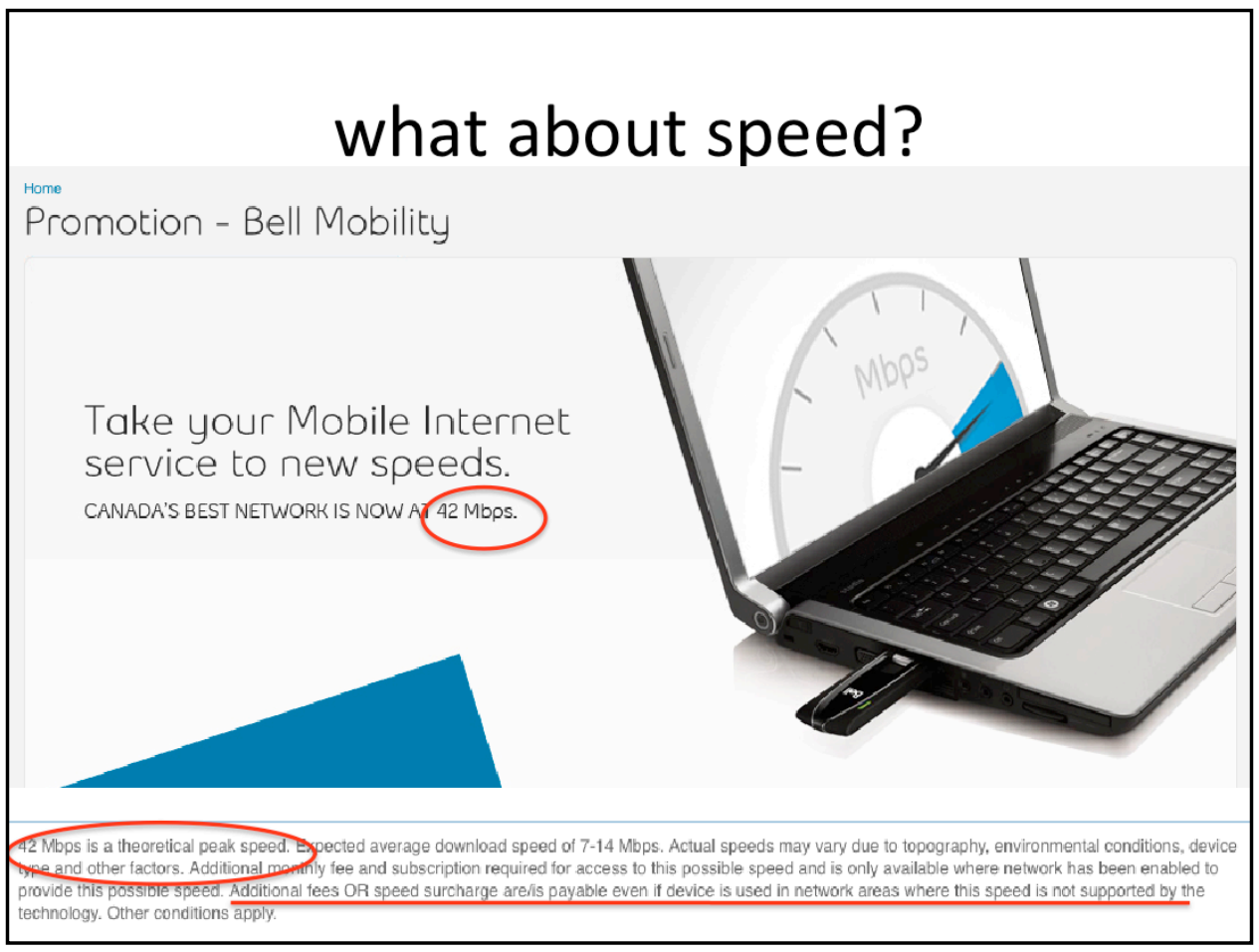

bell.ca 


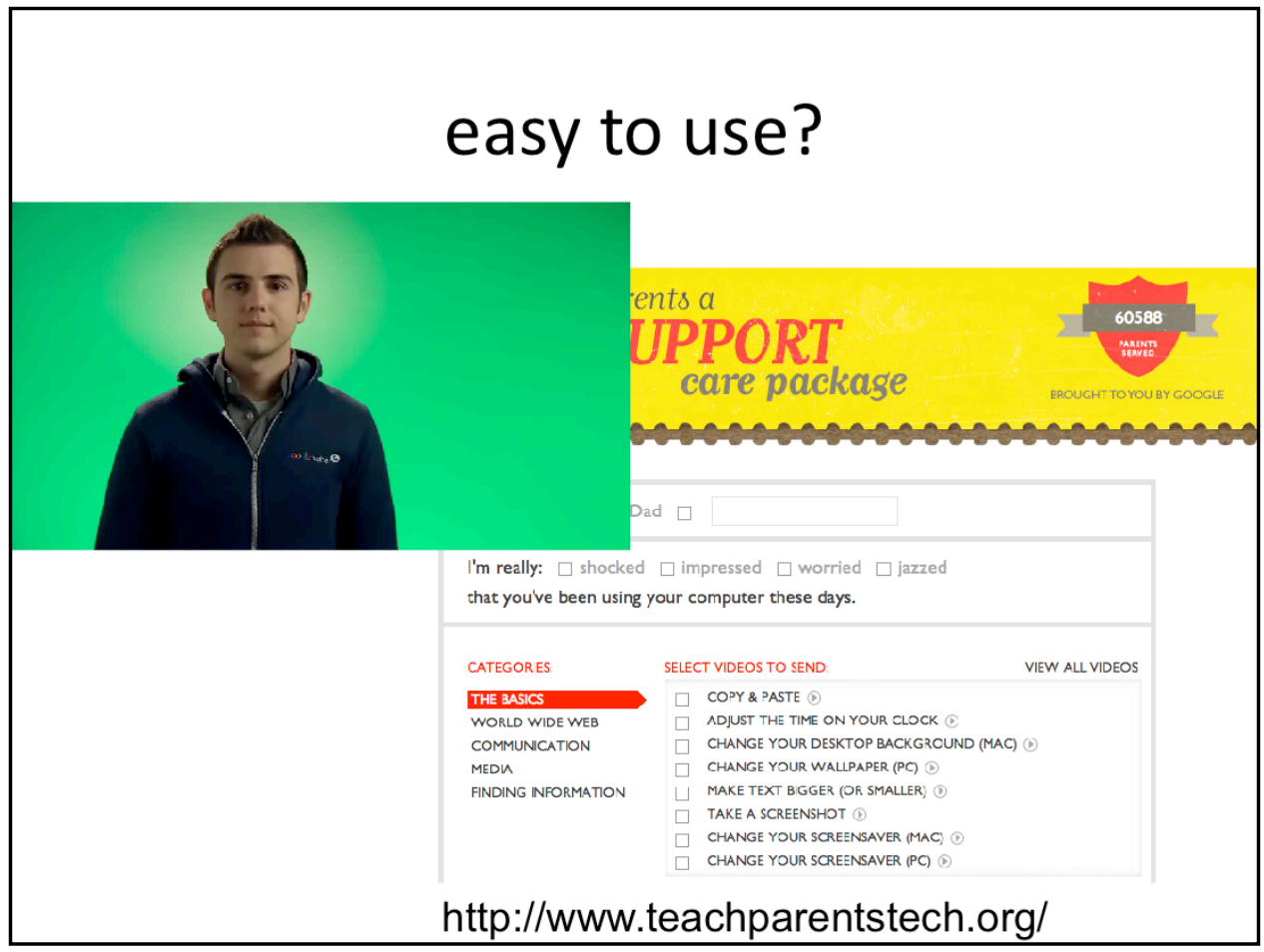

http://www.teachparentstech.org/ 


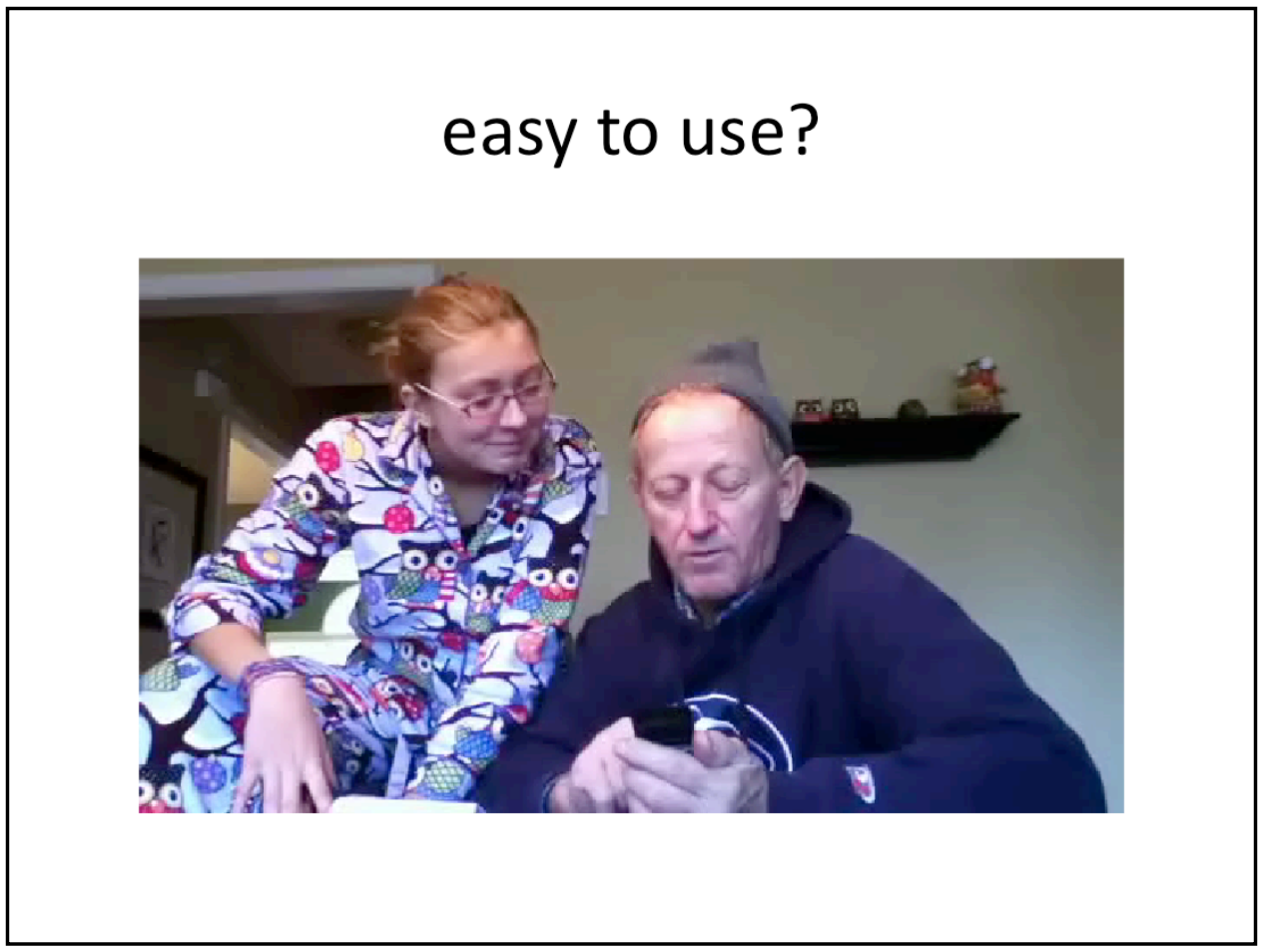

Teaching Pop Pop How to Use His Cell Phone: http://www.youtube.com/watch? $\mathrm{v}=\mathrm{PX} 2 \mathrm{attmH} 3 \mathrm{Q} 8 \mathrm{http}: / / \mathrm{www}$.youtube.com/watch?v=PX2attmH3Q8 


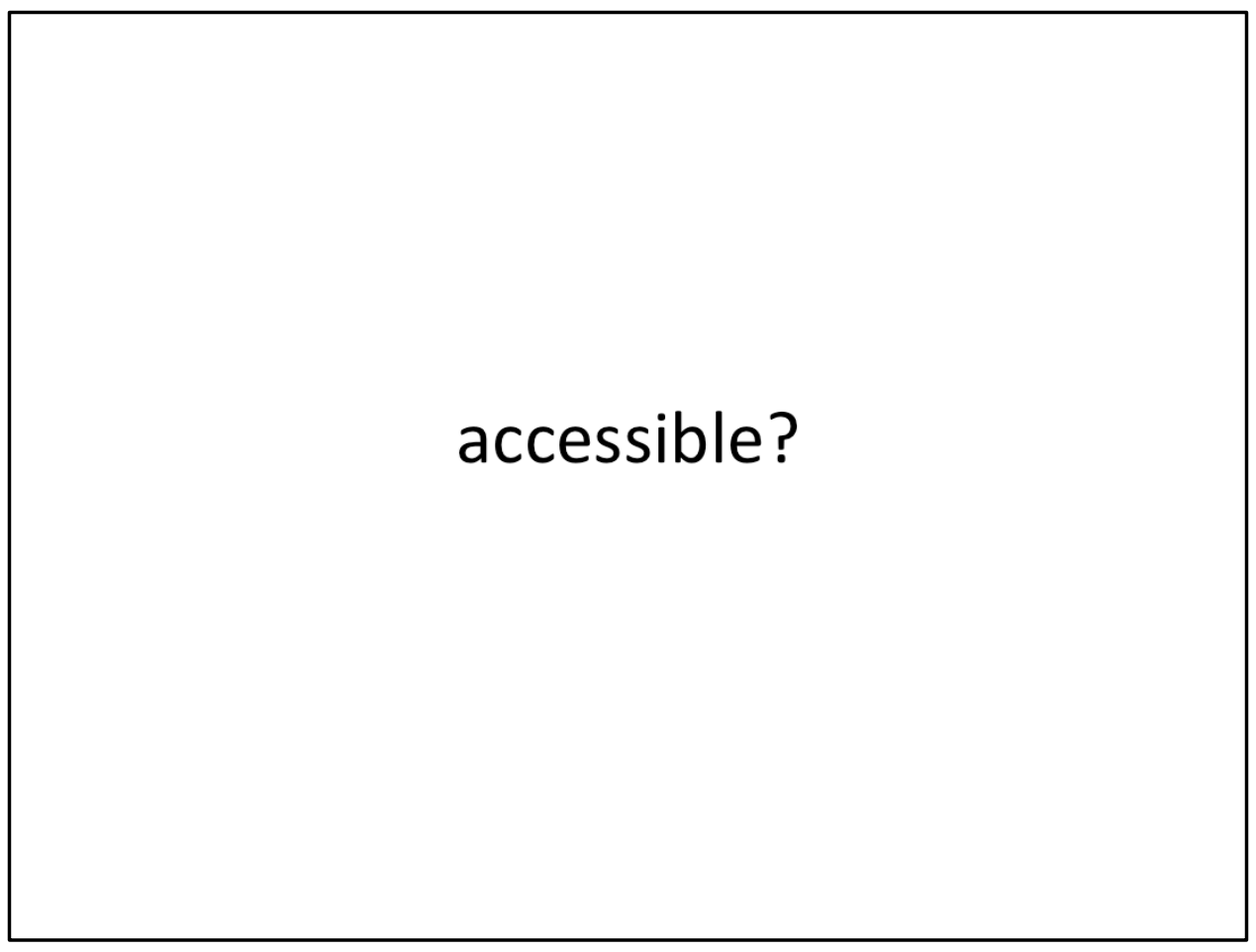




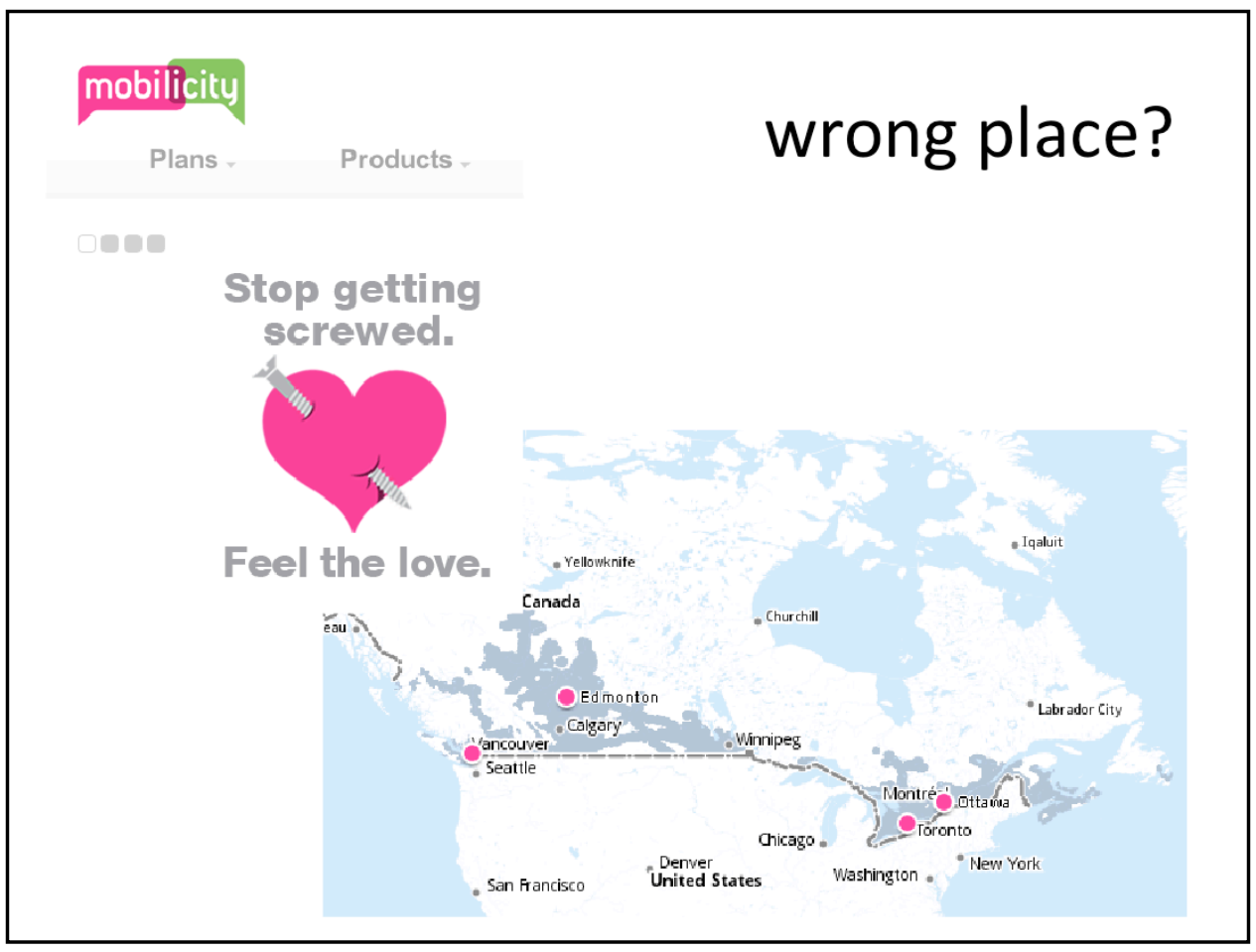

mobilicity.ca: competitive plans in a limited footprint 


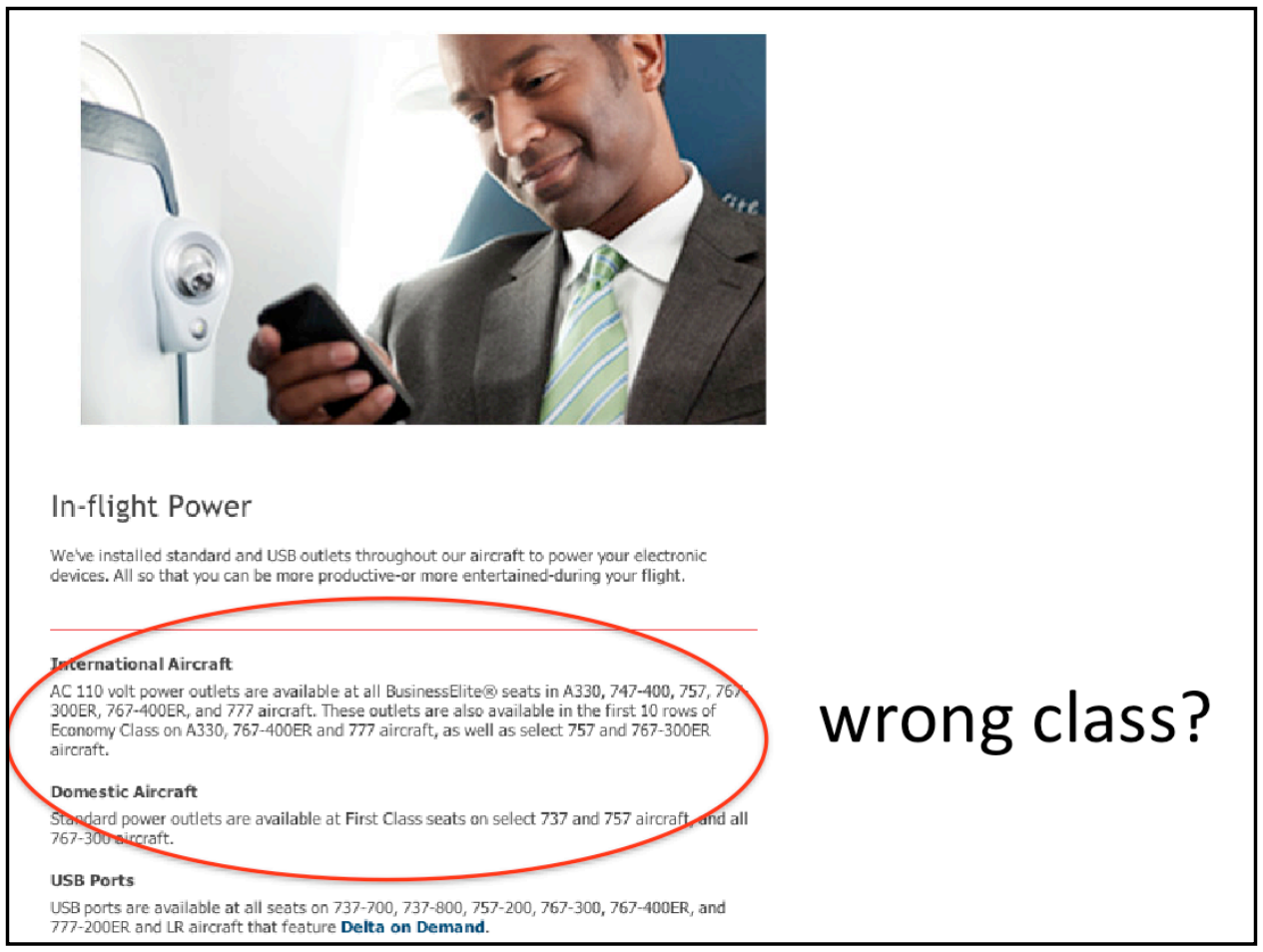

Delta airlines in-flight power: http://www.delta.com/traveling_checkin/ inflight_services/products/power.jsp 


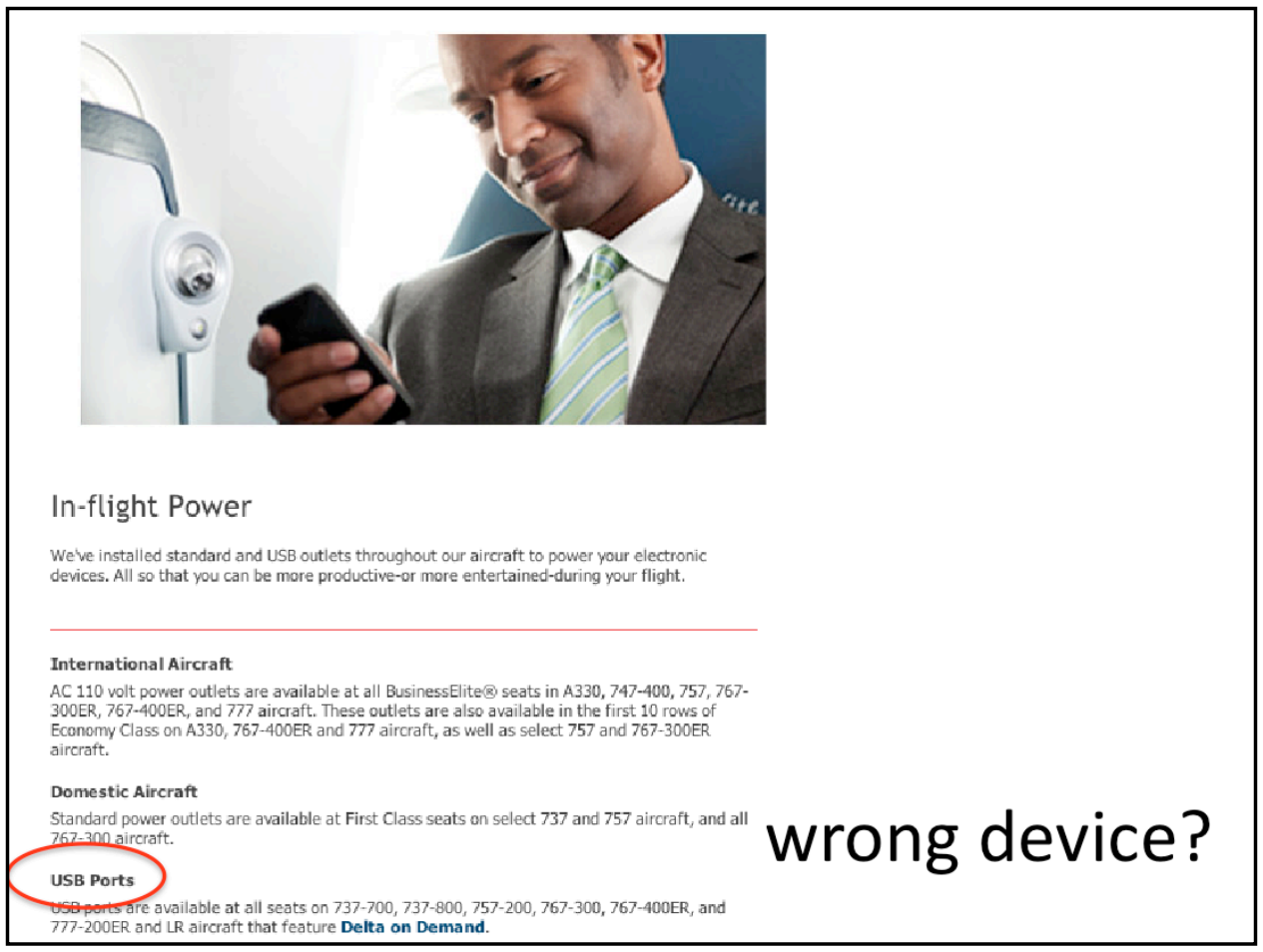

Delta airlines in-flight power: http://www.delta.com/traveling_checkin/ inflight_services/products/power.jsp 


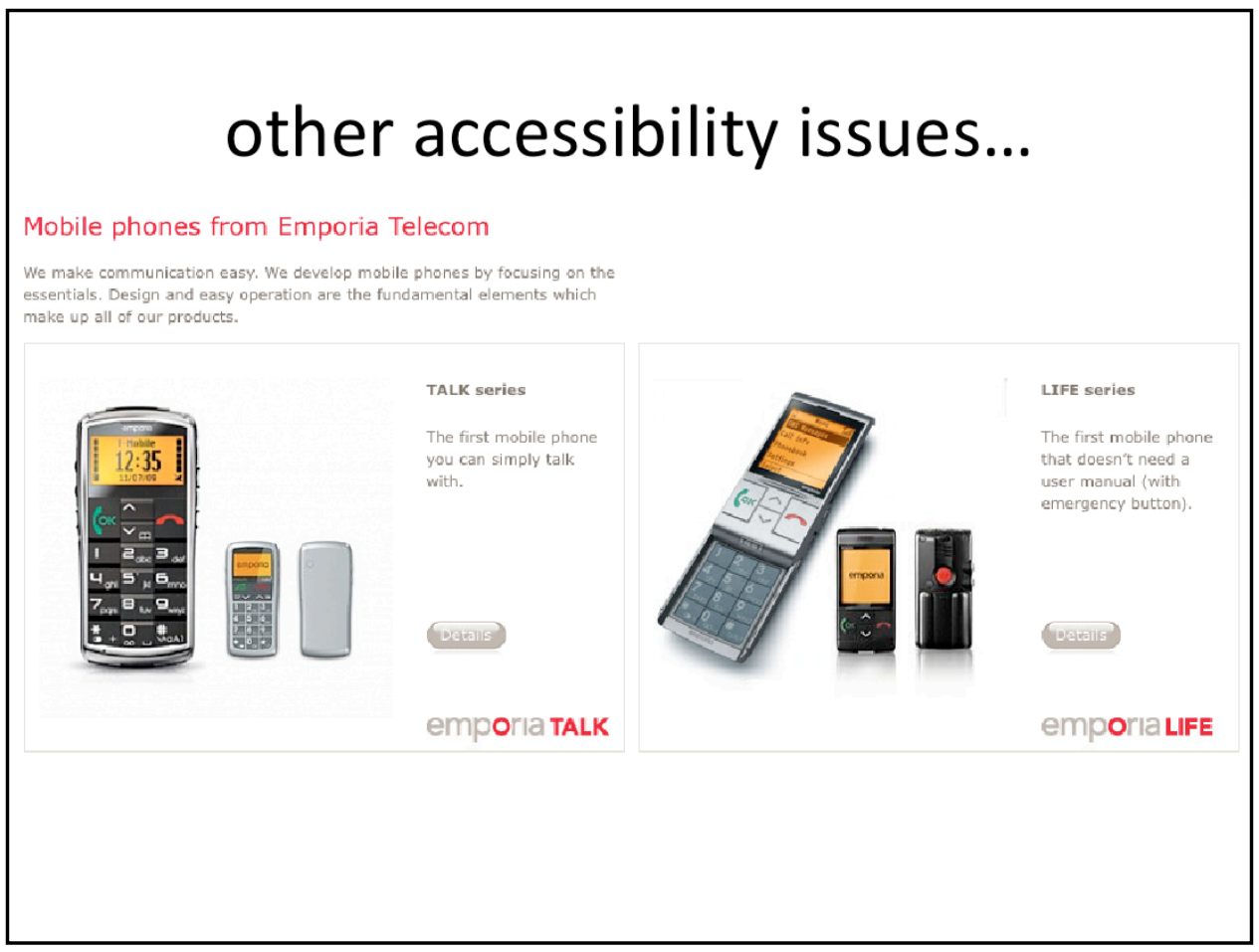

Usability for those with low vision or motor control issues: http://www2.emporia.at/ en/products/ 


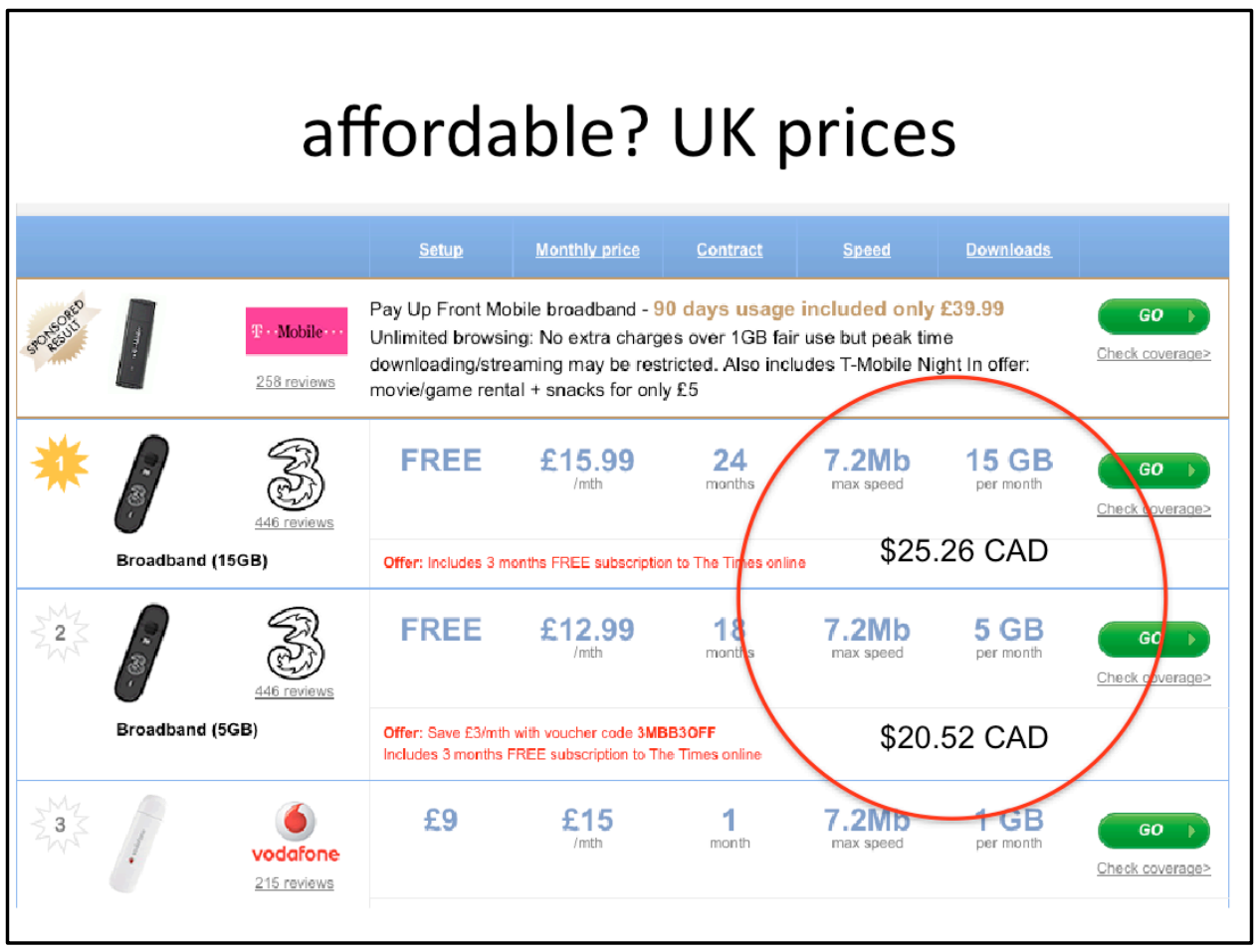

as at Feb. 11, 2011 


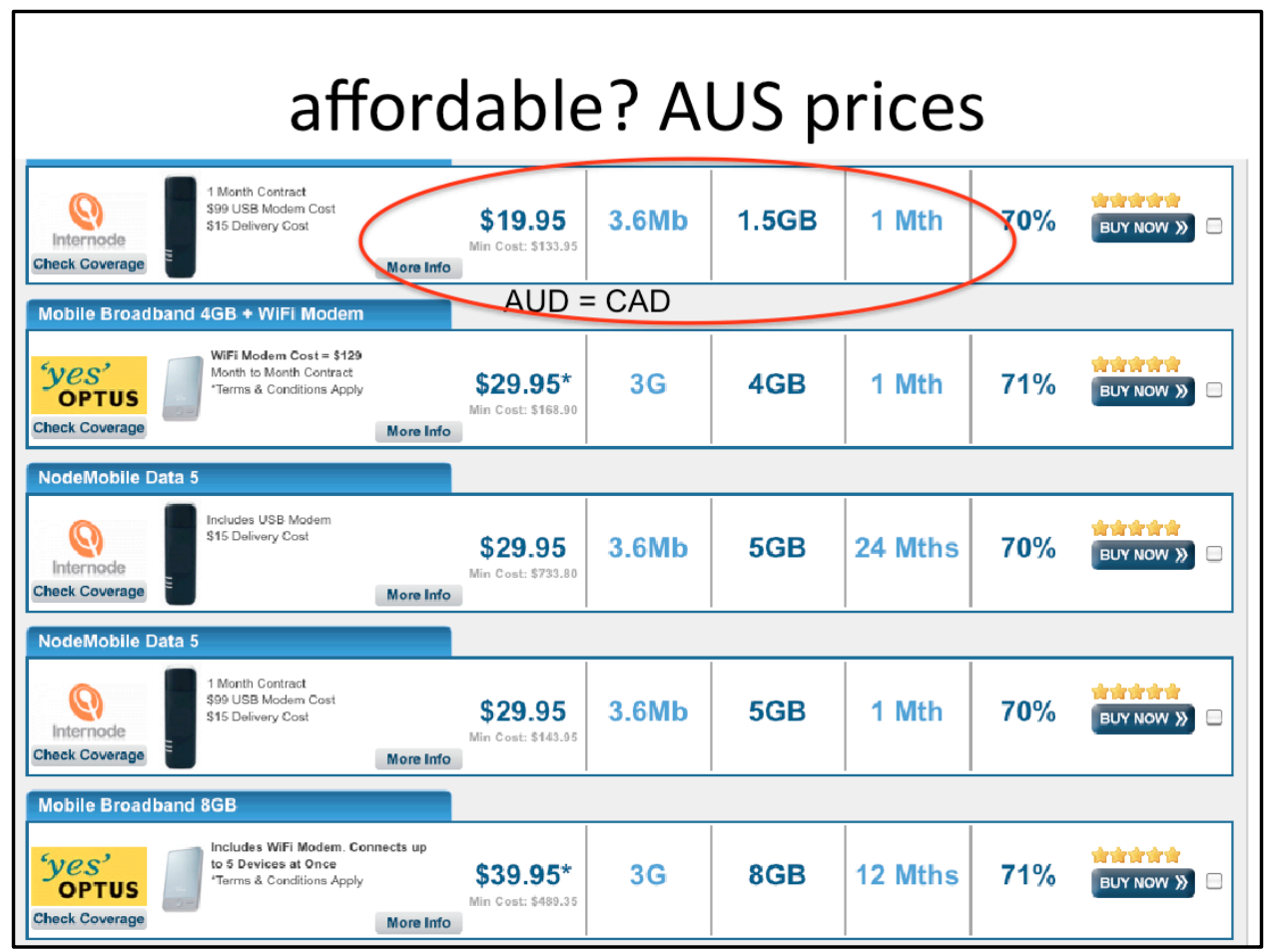

as at Feb. 11, 2011 


\section{affordable? Canadian prices}

Mobile Internet plans Bell

Mobile Internet plans

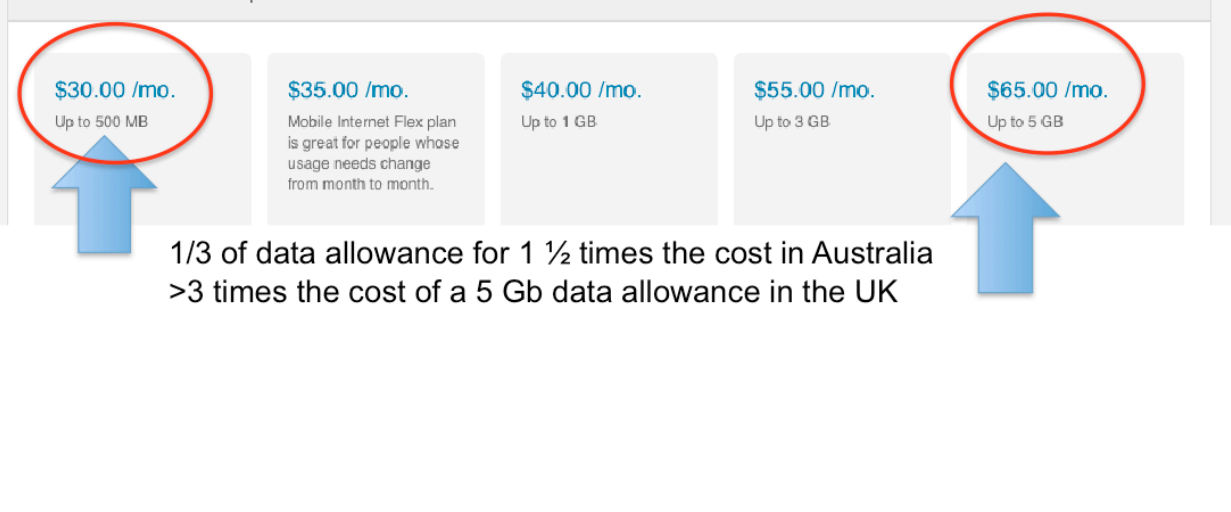

as at Feb. 11, 2011 


\section{locations of constraint (generic?)}

- user-device interface

- locked devices

- form factor constraints (e.g. size, keyboard, battery)

- user-service provider (carrier)

- restricted services (e.g. Skype over 3G)

- device-carrier-network

- Verizon iPhone on CDMA

- AWS spectrum in Canada 


\section{constraints $<-->$ barriers}

continuum:

- income

- literacy/skill level

- location ('anywhere' claims)

- predicament 


\section{remedies (?)}

- user-device:

- design, literacy

- user-service provider (carrier)

- new business models? open networks/devices, 'off network' approach

- more competition (market forces argument)

- device-carrier-network

- policy

- role of wireless in networked society?

- wireless infrastructure in the public interest 